\title{
Improving Growth Outcomes of VLBW Infants: How to Start?
}

\author{
RICHARD A EHRENKRANZ \\ Professor of Pediatrics and Obstetrics, Gynecology \& Reproductive Sciences, Yale University School of Medicine, \\ New Haven, CT 06520-8064. richard.ehrenkranz@yale.edu
}

I n 1977, the American Academy of Pediatrics Committee on Nutrition first stated that the goal of nutritional management of VLBW infants should be to permit the rate of extrauterine growth and the composition of weight gain to approximate that of a normal fetus of the same postmenstrual age, if the infant had remained in utero(1). However, it has become clear that such a goal is more often not reached, especially by ELBW infants(2). The paper by Saluja and colleagues published in this issue of Indian Pediatrics(3) is the first report to confirm that observation on the Indian subcontinent. Although not an unsurprising finding, this report enumerates several issues that should be considered by investigators studying growth of VLBW infants.

Whenever possible, reference intrauterine growth curves should reflect the population studied. Although the authors noted this limitation to their study, they selected Fenton's intrauterine growth reference(4) to determine AGA vs SGA and to calculate $z$-scores. Unfortunately, Fenton's data do not reflect one population; birth weight data are from a Canadian birth cohort and the length and head circumference data are from Swedish and Australian cohorts. In addition, given the high incidence (48\%) of SGA in Saluja's study population, the reader might question the accuracy of gestational age assessment, which was not defined, or the extent that race/ethnicity, life style differences or prenatal care affected birth weight. Therefore, establishing intra-uterine growth reference curves for the Indian subcontinent should be a perinatal research priority. An example of new intrauterine growth curves based on a large cohort based on US data was recently published(5).

Second, while the described fluid and nutrition policy appeared quite reasonable and comparable to currently recommended "early aggressive" nutritional support regimes, several aspects would be subject to significant practice variation. For example, the authors state: "Enteral feeds were initiated as soon as possible, preferably on the first day of life, if haemodynamically stable. Increments of 20-30 mL/ $\mathrm{kg} / \mathrm{d}$ were made as tolerated. Human milk was preferred and once infants reached an enteral intake of $100 \mathrm{~mL} / \mathrm{kg} / \mathrm{d}$, human milk fortifier ....were added to increase the calories to $80 \mathrm{kcal} / 100 \mathrm{~mL}$ with an additional protein intake of $0.6 \mathrm{~g} / \mathrm{kg} / \mathrm{d}$." The early initiation and rate of advancement of enteral feeding, especially with human milk, are admirable. How-ever, early parenteral nutrition support was only offered to those infants not expected to be on full enteral nutrition within the first 5 days of life, increasing the potential for protein and energy deficits, which are difficult to overcome prior to hospital discharge(6). Therefore, fluid and nutrition policies that optimize the transition of nutritional support from initiation to achievement of full enteral nutrition and during maintenance enteral nutrition should be recommended and encouraged.

It is hoped that promoting growth of VLBW infants should lead to improved long term neurodevelopmental outcomes(7). In order to change practices that support that goal, an understanding of the growth outcomes achieved with current practices is essential. Saluja and colleagues should be commended for initiating that process. 
Funding: None.

Competing interests: None stated.

\section{REFERENCES}

1. American Academy of Nutrition Committee on Nutrition. Nutritional needs of low-birth-weight infants. Pediatrics 1977; 60: 519-530.

2. Ehrenkranz RA. Early, aggressive nutritional management for very low birth weight infants: What is the evidence? Semin Perinatol 2007; 31: 48-55.

3. Saluja S, Modi M, Kaur A, Batra A, Soni A, Garg P, et al. Growth of very low birth-weight Indian infants during hospital stay. Indian Pediatr 2010; 47: 851-856.
4. Fenton TR. A new growth chart for preterm babies: Babson and Benda's chart updated with recent data and a new format. BMC Pediatr 2003; 3: 13-22.

5. Olsen IE, Groveman SA, Lawson ML, Clark RH, Zemel BS. New intrauterine growth curves based on United States data. Pediatrics 2010; 125: e214e224.

6. Embleton NE, Pang N, Cooke RJ. Postnatal malnutrition and growth retardation: An inevitable consequence of current recommendations in preterm infants? Pediatrics 2001; 107: 270-273.

7. Ehrenkranz RA, Dusick AM, Vohr BR, Wright LL, Wrage LA, Poole WK, et al. Growth in the neonatal intensive care unit influences neurodevelopmental and growth outcomes of extremely low birth weight infants. Pediatrics 2006; 117: 1253-1261. 